\title{
An ethnography of permanent exclusion from school: revealing and untangling the threads of institutionalised racism
}

Anna Carlile ${ }^{1}$

Department of Educational Studies, Goldsmiths University of London, UK.

\begin{abstract}
This article focuses on the administration of disciplinary exclusion (expulsion) from school. It identifies a number of social boundaries between people that negatively affect students subject to permanent exclusion, to the extent that they can be seen as constituting incidents of institutional racism. For example, the high statistical currency of the English language and the lack of adequate translation facilities are shown to constitute social boundaries between people that undermine the participation of parents in school exclusion and inclusion processes. Age assessments for immigrant and refugee children are also seen to affect institutional responses to individual cases of permanent exclusion from school. Assumptions about what excluded students 'need' are found to sometimes be made on the basis of reductive skin-colour labels, and a disconnect is discovered between the discourses that school and family are socially authorised to adopt in discussing students at risk of exclusion. It is recommended that institutional racism in schooling is acknowledged and acted upon by both policy makers and practitioners.
\end{abstract}

\section{Introduction}

This paper seeks to investigate evidence of institutional racism experienced by young people who are at risk of being 'permanently excluded' (expelled) from schools in an urban area in the South of England. Permanent exclusion can be seen as a critical incident: a moment at which 'the system' might be said to have failed. Because of this, it is a useful lens through which to investigate the effects of institutional prejudice. The article represents part of a piece of ethnographic research, undertaken 'on the job’ as I worked within the Children's Services Department in a large urban local authority, ${ }^{2}$ 'Enway'. ${ }^{3}$ The focus of the research was on the causes and effects of permanent exclusion from school on young people and on employees of Enway

\footnotetext{
${ }^{1}$ Email: a.carlile@gold.ac.uk

${ }^{2}$ A 'pcal authority' is the local government in an area of England, which runs public services, usually including education and social services.

3 'Enway' is a pseudonym, as are all other names of people and places in this article in order to protect anonymity and confidentiality.
} 
Children's Services and related institutions also working with young people who had been excluded from school. ${ }^{4}$

The next sections will define institutional racism, explain how permanent exclusion works in England, and describe the institutional framework within which I was working at Enway. A section on methods will be followed by a series of case studies addressing some of the social boundaries between people which, I will argue, define the presence of institutional racism: issues around language, age assessments made in the context of immigration and border administration, visual perceptions of ethnicity, and the discourses different groups of people are authorised to use.

\section{Institutional racism in administrative practices of representation}

By 'institutional racism', I am referring to that racially motivated prejudice which the Macpherson Report in $1999^{5}$ on the murder of Stephen Lawrence found throughout the police force in England. Stephen Lawrence was a young 'black British' teenager who was beaten, stabbed, and killed by several white youths at the bus stop on his way home from school one evening. None of the perpetrators was brought to justice, and the Macpherson Report found that the police investigation was fundamentally flawed, largely because of problems caused by what was identified as institutional racism. This constitutes the effects of an institutionalised indirect or direct prejudiced treatment of a person on the basis of essentialising representations of their ethnicity, 'race', or cultural identity. In other words, Macpherson found that police prejudice towards Stephen Lawrence's ethnicity caused them to make decisions during their investigation and report of evidence which had the effect of privileging the white suspects. In order to think about the situation in Enway, I am using the concept of institutional racism to refer to a weight of established practices and decisions which amounts to administrative policy. The institutional racism in this case is expressed through representations of young people in paperwork and in professional talk, relating to their perceived 'race', ethnicity or nationality. These representations are woven throughout institutional protocol with inequitable consequences.

\footnotetext{
${ }^{4}$ See also Carlile (2010)

${ }^{5}$ The Stephen Lawrence Enquiry: report of an enquiry by William Macpherson of Cluny presented to the English Parliament by the Secretary of State, February 1999.
} 
This article will develop the idea that institutional prejudice underpins some of the causes of permanent exclusion from school. This prejudice involves the exercising of normative power, because it is expressed through the administrative (mis)representation in paperwork and in professional talk of children and young people at risk of or subject to permanent exclusion. Policy suffuses the activities of those in the employment of local government with the letter and the spirit of central governmental authority, or as Foucault (1977) puts it, 'the gradual extension of the mechanisms of discipline ... their spread throughout the whole social body' (209). So this article will show how that state power is expressed to some extent through institutional racism.

The permanent exclusion-related events described below can be described as instances of 'institutional racism' because they do not necessarily constitute the direct prejudice of one person: what Zizek (2008) calls ‘subjective violence’. Instead, they emerge as 'objective violence' (Zizek 2008); the deeper effects of the practice of exclusion protocol, often expressed through 'gatekeeping' practices. These can include school admissions protocol for permanently excluded students. As Sivananden (2005) states, 'the racism that needs to be contested is not personal prejudice, which has no authority behind it, but institutionalised racism, woven over centuries of colonialism and slavery into the structures of society and government.'

Important research has been undertaken into disciplinary exclusion from school, hitherto largely involving research with pupils, parents and school staff (Osler and Vincent 2003; Cooper 2002). School exclusion in terms of elements of 'race' and ethnicity has also been researched extensively, with Gillborn (2009) speaking from within a Critical Race Theory perspective, which sees 'white supremacy' as at the root of socio-economic and other societal and institutional inequities. Blair (2001) places the problem within a blend of institutional and historical socio-economic and Critical Race Theory frameworks. This article is intended to broaden the discussion beyond schools to incorporate the administrative practices of those in local government responsible for implementing education policy across a geographical area, and the work of non-school professionals such as social workers and those who work within the youth criminal justice system. 


\section{A note on the relationship between gender, 'class', and institutional racism}

In Enway, as in some other parts of England (Evans 2007), thinking about educational attainment and exclusion could have been said during the time of the research (20052007) to be 'located within wider contemporary panics about boys' educational 'underachievement' ... (which are partially attributed) to the rise of feminism and the 'overachievement' of girls' (Archer and Yamashita 2003:116; see also Osler and Vincent 2003). And concerns focused specifically on boys can serve to exclude a discourse that tackles inequity on the grounds of 'race' and ethnicity within gender and class groups. Tomlinson (2005) has identified the fact that 'anxieties in England about 'boys' underachievement' were in fact about white male underachievement, and the overall improvement in girls' school performance masked the educational difficulties of significant numbers of girls from minority backgrounds' (161; see also Wright 2005; Osler and Vincent 2003). It should also be noted that 'class, migration, and ethnicity are integrally connected concepts’ (Archer and Yamashita 2003: 122). I seek to avoid a glib conflation of 'race' or ethnicity with a sort of generalised concept of social deprivation, as this can have a blurring effect, distracting focussed attention from the effects of institutional racism and classism. But studies of the effects of a person's 'race' or ethnicity on their educational success acknowledge that the 'class fractions' found within an 'ethnic group' are importantly revealing and constitutive of a person's experience (Blair 2001; Ball et al. 2002; Francis 2005). So, although I am not explicitly addressing the intertextuality of experience and representation here, the focus of this article should be read with an acknowledgement that experiences to do with 'race' and ethnicity are inextricably intertwined with 'class' and gender.

\section{What is permanent exclusion from school?}

Officially, in England, a permanent exclusion is made as a final step when a school has 'tried everything available' to support the continued inclusion in mainstream school of a child or young person. This may have included academic and emotional support in school from learning support assistants and learning mentors. It may also have involved assessment and intervention from 'outside' professionals such as an educational psychologist, a child and adolescent mental health services (CAMHS) professional, a social worker or a youth offending team officer. The child or young person may have spent time in a small supported classroom such as a learning support or pastoral support unit in or out of school, sometimes as part of a programme of 
support attached to a fixed term exclusion (suspension) from school. He or she may also have been given the opportunity to make a fresh start at a new school on a trial basis. This is known as a 'managed move', the implications of which are discussed further, below.

In order to enact an official permanent exclusion, the head teacher must present a complex series of paperwork before a Governor's Panel. School governors are volunteers, responsible for ensuring that the head teacher runs the school according to the law and with the educational and social needs of the children and the community at the centre of decision making. The paperwork must show evidence that the student has been given a Pastoral Support Plan, which coordinates the interagency support strategies and tracks a series of behavioural targets. Unless the permanent exclusion is on the basis of a serious one-off offence, identified in school policies as an excludable 'offence' (for example, bringing a weapon or drugs to school), the Pastoral Support Plan must show that the school has given the student an opportunity to improve his or her behaviour. Where exclusion is not for a one-off offence, students are often excluded for what is known as 'persistent disruptive behaviour'.

Once an exclusion has been agreed at the Governor's Hearing, parents have the opportunity to either accept the offer of a new school place, if one can be found; or a place at the Pupil Referral Unit, which supports excluded students in smaller classes and with a focus on behaviour and reintegration; or to apply to an Independent Appeals Panel to have the exclusion revoked. The local authority will ask the school to repay the money it has been given to pay for the education of the excluded student, and this usually amounts to between $£ 3500$ and $£ 5000$.

\section{Unofficial exclusions}

In order to try to avoid permanent exclusions, the schools I worked with in Enway often tried to find alternatives, and one of these was called the 'managed move'. However, managed moves in Enway often constituted what might be called ‘unofficial exclusions'. Parents were frequently offered a new school placement under threat of permanent exclusion, and because they did not want this on their child's record, they would often accept it, even though it removed their right to an appeal. Fixed term exclusions and 'temporary' placements in learning support and pastoral 
support units often amounted to an unofficial exclusion, too, with students spending several weeks or months out of the mainstream classroom. These strategies can be seen as supportive alternatives to disciplinary permanent exclusion. But they also benefit schools because they remove what is often seen as a 'difficult' student; keep official exclusion numbers down (and these are inspected by the government); and prevent the local authority from fining them.

It is because of this that when I discuss the causes and effects of permanent exclusion from school, I do not only consider those who have been 'officially' excluded, but also those who have been affected by the existence of permanent exclusion from school as an option. Just the existence of a permanent exclusion as a strategy, even if it is not implemented, can negatively affect children. The ethnographic segments, below, will illustrate how this worked in Enway.

\section{The Enway 'Hard to place' Student Placement Panel}

I worked in Enway during the period of my ethnographic research as a Student Support Officer, and I refer throughout this paper to the source of my case-load: 'the Panel', or 'the 'Hard to Place Student Placement Panel'. This multi-agency, senior management-attended Panel, held every two weeks in Enway, discussed the fate of around twenty-five young people each time. Each one was being considered for a school place following an actual or threatened permanent exclusion or a similar set of complex needs. It was from this Panel that in my role as Student Support Officer I drew my caseload of students to support. The Panel meeting was chaired by the Head of Inclusion (Behaviour), and always included three head teachers who took it in turns to attend the Panel meetings, speaking on behalf of their colleagues. The broad range of professionals attending the Panel reflected the DfES's ${ }^{6}$ drive for 'joined-up' support planning. So, usually in attendance was the Head of School Admissions; the Exclusions Officer, who attended all permanent exclusion hearings; the head teacher at the pupil referral unit (PRU); an educational psychologist; a Safeguarding and Social Care manager; ${ }^{7}$ a Special Educational Needs (SEN) officer; a Youth

\footnotetext{
${ }^{6}$ Department for Education and Skills, now the Department for Education.

${ }^{7}$ A senior social worker.
} 
Offending Team officer; ${ }^{8}$ a representative from the Attendance Advisory Service; ${ }^{9}$ the chief executive at an independent alternative education unit, ${ }^{10}$ the services of which were bought in by the local authority area; and the Student Support Officer (myself), who carried out many of the decisions made by the Panel. Professionals from CAMHS ${ }^{11}$ were invited, but never attended. It was in essence a 'gatekeeping' panel, and it had the power to place students in one school or another, or in an alternative education unit, dependent on what was often called their 'needs'.

Much of my ethnographic data was drawn from Enway Panel meetings. After one such Panel, I wrote in my notes

A Youth Offending Team education officer made a 'joke' at the last Student Placement Panel about how the most appropriate education placement for a Traveller student would be 'tied to a tree'. There was much laughter. At this week's Panel, in an attempt to redraw the ground rules, the Chair reminded the Panel members that 'in Enway we treat all members of society with respect'. Her comment was met with much groaning, giggling and rolling of eyes. It was as if the statement was 'political correctness gone mad' and that racist jokes about Traveller children should be acceptable. Later on, a long conversation about whether a young person's mother was capable of educating her at home was only halted when it was pointed out that there was no evidence that she could not, and that the only information we had about this student was her name, which 'sounded Indian'. ${ }^{12}$ There was an embarrassed lull as Panel members acknowledged that they had been making assumptions based on the girl's name. But it's difficult to keep pointing these things out; it seems that around three such comments at each Panel is all that can be tolerated before people start 'tutting' and muttering about getting on with the job at hand.

Field-notes, February 2005

It was on the basis of these kinds of comments that I felt it important to consider the role of institutional racism. The comments reveal a mixture of what Zizek (2008) calls 'subjective violence' in the form of 'personal prejudice' (Sivananden 2005) and the 'objective violence’ (Zizek 2008) of systemic prejudice. The personal prejudice, I felt,

\footnotetext{
${ }^{8}$ Responsible for supporting and enforcing the orders given to young people who had become involved with the youth justice system.

${ }^{9}$ These officers ensure that students attend school and can fine their parents where attendance becomes a marked problem.

${ }^{10}$ A private school delivering education for children who were unable to attend mainstream school due to behavioural issues.

${ }^{11}$ Child and Adolescent Mental Health Services.

${ }^{12}$ That is, South Asian.
} 
could be conceived of as bleeding out around the entrenched splinters of institutional prejudice; constituting a symptom of it. So I suspected that institutional prejudice with its possible causal relationship with personal prejudice, exacerbated the negative experiences of students at risk of or subject to a permanent exclusion from school, and may be found to constitute a partial cause of exclusions.

\section{Ethnography as reflective practice: revealing and untangling the threads of institutional racism}

The field-notes I made as a participant-observer - a researcher in my own workplace underpinned my approach to reflective and informed practice. The findings in this paper arise from the implementation of a series of ethnographic fieldwork strategies participant observation, unstructured interviews, and several months of note-taking in the field. During the 36 month period of my research between 2005 and 2008, I remained in my job as a Student Support Officer in Enway, and the ethnography focussed on the people I interacted with as part of my job. My work involved supporting young people and parents to try to ensure their views were taken into consideration and to administer and enable the transition into their new school. I set up and ran multi-agency meetings and was responsible for making sure each member of the team carried out what was necessary to support the young person the centre of the transition. My aim was to ensure that the head of year, ${ }^{13}$ the student and the parents or carers were doing what they could to empathise with each other. The goal was to collaboratively develop a plan of support that would enable the student to benefit from his or her education without unduly disrupting that of other students. Pastoral support planning was developed with input from people as diverse as a housing support worker, an educational psychologist, a police officer from the Youth Offending Team, and a social worker. Because of the conflicting and often authoritative opinions of these professionals, it was crucial that I remained reflective in planning for support.

For example, during one student support meeting, I heard the same student described as 'very dangerous' by the schools' police liaison officer; 'learning disabled' by the educational psychologist; 'a nasty piece of work' by the senior teacher; 'a young

\footnotetext{
${ }^{13}$ A senior teacher with pastoral care responsibilities for each age-group.
} 
person with a lot of potential, caring for her alcoholic father' by the social worker; and 'in need of an Anti Social Behaviour Order ${ }^{14}$ by the housing officer. It was important that I did not allow the collective and conflicting biases engendered by years in each of these professions to affect constructive support planning for the student. And with only one of the five professionals advocating positively for the student, part of my role was to ensure the constructive, empathic view was taken seriously. The ethnographic approach requires deep observation and description, and a protracted amount of time spent consciously in the field. The method proved indispensable for understanding these inter-professional conflicts.

My role also required a degree of self-awareness. I learned through the continued reflexivity required by the ethnographic methodology that I tended towards a resistance against expressions of authority. Ethnographic methodologies require researchers to 'monitor closely and continually their own interactions with participants ...' (Cohen et al 2000:141), and I found that my field notes became the vehicle for this endeavour. I wrote before, during, and after meetings, and the ethnographic impulse to notice, listen, and reflect became an indispensable strategy in my work with young people and families. It also allowed me to confront and acknowledge my own filters, and I learned to interrogate my initial reactions to things I observed or experienced.

As a central component of my ethnographic methodology, the practice of participant observation allowed me to gather information from the different spaces in which inter-professional negotiations were conducted and the private lives of students and parents erupted into the public physical and virtual spaces of local authority institutions. These spaces included housing offices, school meeting rooms, institutional corridors, behaviour logs, computer databases, and reports. The approach worked to reveal and untangle threads of institutional racism within the messy, complicated world of permanent exclusion because it benefitted from 'the capacity to connect diverse and even contradictory discourses to patterned activities, institutional interests and personal relationships that span a variety of social realms ...' (Dyck in Amit 2005: 41). A public institutional space, such as a school, can be defined as a

\footnotetext{
${ }^{14}$ A judicial injunction tailored to the young person’s misdemeanours
} 
place where 'diverse' groups of people come together to interface with a common authority. Ultimately, it is the fact that my informants (and myself, as an employee) were all subject to the power exerted by Enway's Children's Services Department that rendered us all a group - albeit bringing with us diverse and contradictory discourses amenable to ethnographic description. As a Student Support Officer/researcher, my notes were integral to my work, but also became a rich source of data to start looking for patterns in the complicated picture of permanent exclusion. Some of the patterns that began to emerge were, I felt, indicative of institutionalised racism.

\section{On not essentialising}

In talking about 'race', ethnicity, national identity, or culture, it is difficult to categorise people without doing them the disfavour of essentialising their alleged experience (Hall 1992; Gilroy 1998; Ball et al. 2002). In a time when places and people can be described as 'multicultural', 'multiracialised', or 'culturally entangled' (Archer and Yamishita 2005:120), any essentialising description based on 'race' or ethnicity constitutes a projection that ignores the complexity of people's lived experiences. Further complicating the issue, because of social and professional linguistic filters (known sometimes derogatively as 'political correctness'), people working in the children's services department and schools of Enway during the period 2005-2008 were sometimes not verbally direct about the judgements they were making on the basis of a person's perceived 'ethnic identity'. For example, the racialised, negative assumptions made about the two children in the field-notes quoted above emerged in comments about being 'tied to a tree' and about being incapable of home education, rather than in a direct naming of their ethnicity. ${ }^{15}$

Seeking a less essentialising model for investigating institutional racism, I looked to Eriksen (1995), and anthropologist, who explains that whilst “cultural traits' do not entail ethnicity ... the focus of research ought to be the social boundaries between groups rather than the 'cultural stuff' they contain ... ethnicity must therefore be seen as an aspect of a relationship, not as a property of a person or a group' (251). In other words, 'race' and ethnicity are relative concepts (Eriksen 1995; Gilroy 1987), and assumptions based on 'ethnicity' have as much to reveal about those making the

\footnotetext{
${ }^{15}$ This would still have been essentialising, but would have more easily revealed the judgements as being based on racist stereotyping.
} 
assumptions (and their ethnic-cultural discourses) as those about whom assumptions are being made.

In looking at racism, then, instead of looking at my perception of the experiences of groups of students defined by 'cultural stuff', I have tried to identify and describe some of the elements focussed on by Enway professionals in making school placement and pastoral support judgements about excluded students. In other words, my focus is on seeking out the elements that reinforce social boundaries, rather than on the groups corralled within those boundaries. These reinforcing elements will include, below, discussions of language and translation; age assessments made on young asylum seekers and refugees as they enter the country; assumptions made on the basis of skin colour labels; and the differences between the discourses parents and school professionals are (socially) authorised to use in discussing a young person's behaviour. These elements, I suggest, in reinforcing social boundaries, comprise evidence of institutional racism.

\section{Features of social boundaries concerned with 'race' and ethnicity in the administration of exclusion from school}

\section{Language (i): Statistical significance}

One way in which institutional racism can emerge is through the methods for 'counting' students in the statistics-gathering exercises that result in a school's allocation of funding and its placement in the league tables. League tables in England, which are published annually in the national newspapers, measure schools' 'success' according to the attainment of their students in public examinations. However, 'value added' scores, which measure the progress of a school's pupils from their baseline scores (as opposed to their final grade), are not generally viewed by media, government or parents as important in the final league table rankings. This means that a school with students who are more socially, economically and linguistically disadvantaged may rank below a school with advantaged students, even if its students have achieved more progress.

Head teachers and Panel members in Enway knew that where students had been educated overseas in non-English-speaking countries, their public examination results are not counted in the league tables. The government guidance on this (DfES April 
2004) states that 'if pupils have English as an additional language they are exempt from inclusion in school and LEA ${ }^{16}$ league tables for a two year period' (section 4.2). Because of this, at the Enway Panel, there was less perceived 'risk' inherent in taking in such students. However, because $\mathrm{GCSE}^{17}$ examination courses take two years, this dissuaded head teachers from taking on students who spoke English as an additional language at the beginning of Year $10,{ }^{18}$ as by the end of the course, they would have been at the school for two years and would have their results counted.

These rules constitute a 'social boundary between people' and they had the effect on Panel members' school placement decisions which amounted to institutional racism. For example, the Panel one day discussed whether a student who had come to live in Englnd from Pakistan should be placed at a mainstream school. However, he had already spent two years in a school in another part of England, and one head teacher, ${ }^{19}$ reluctant to take the student on roll, said, 'If they come from overseas, never having been in a British school, they don't count on our statistics so we don't mind - well, some of us don't - but if they've been in any British school they count'.

Another head teacher replied, 'Not to put too fine a point on it, we took fourteen Nepalese last year and all got fantastic grades in mathematics; couldn’t speak a word of English ${ }^{20}$ [and therefore did not achieve good grades in English]- we'll never take a Nepalese again; (because of) these ridiculous statistics! 21

Panel students who were perceived as less desirable to a school due to the fact that they had been at risk of or subject to a permanent exclusion, then, were even less likely to be welcomed on roll at a mainstream school if their language or lack of experience with the English National Curriculum meant that they were less likely to get 'the right grades'. The statistical significance given by the state to a language spoken by a group of students could be described as one of 'the social boundaries between groups' (Eriksen 1995) - the space which must be observed when we are

\footnotetext{
${ }^{16}$ Local Education Authority.

${ }^{17}$ General Certificate in Secondary Education.

18 Aged 14-15.

19 Principal.

${ }^{20}$ This is clearly untrue, as due to the text content of the exam papers it would not be possible to get an A* in maths without 'a word of English'

${ }^{21}$ The case of Nepalese students is especially interesting, as I observed during my research that they were extremely popular amongst teachers due to a perceived 'politeness' and deference.
} 
thinking about the effects of 'ethnicity', according to Eriksen. As such, a focus on the Panel's attitude to a student's language can reveal threads of institutional racism in the education system.

\section{Language (ii): Translation}

Issues around translation also exemplify institutional racism in action and exacerbated under the pressure of exclusion from school.

When a student is excluded, or moved due to the threat of exclusion from school, their parent will usually have already been through several school meetings. Some of these meetings will have required the parent to make difficult decisions about, for example, which school they would like their child to move to. If that parent's first language was not English, they may have had to make these decisions based on information they have not fully understood and so would have struggled to ask questions about. Often, in Enway, the excluded child was asked to translate difficult and emotionally risky information for their parent, and of course the situation in which they found themselves may have precluded them from making a totally accurate translation. They may not, for example, exactly translate for their parent a teacher's comment about their own 'outrageous and immature behaviour'.

Schools often did not identify the need for a translator: one school administrator looked pensive when I suggested that there may be possible translation needs for a Syrian parent, telling me doubtfully, 'there's nothing on the form!' I noted that parents often pretended that they know more English than they did. They would sit in a meeting, nodding and smiling, but on checking the situation, I would find that this was because they were embarrassed to ask for help, or did not know it was available. Translation services were in any case expensive and difficult to arrange. Even where a school qualified for free translation support (and in Enway there was funding for this), inclusion staff may not have known about it; there may have only been one translator available for the required language, and translators may have been unavailable when they were needed. When they were available, it was often difficult for the translator to understand the processes of exclusion and inclusion through which schools were taking their students, and this caused further problems. The stories of Sarama and Kim, below, exemplify these difficulties. 


\section{Sarama}

Sarama, an Eritrean student at Enway College, was at extreme risk of permanent exclusion. At twelve years old, she was often in danger, spending the night walking around the streets with her friends, drinking alcohol, and getting into cars with people she did not know. At school she spent the day restlessly pacing the corridors, screaming at teachers, and refusing to go into lessons. I first met her mother, Zula, on a home visit. I sat listening in her tidy, warm living room, an Eritrean flag on the wall and an Arabic TV channel playing on a large set in the corner. Speaking Arabic through one of my colleagues (an unofficial and empathic translator), and quietly weeping as she told her story, Zula told me that she had experienced the trauma of war and had escaped Eritrea when Haile Salassi invaded the country from Ethiopia. She had travelled across the Red Sea to Saudi Arabia with her four children, where she had consolidated her knowledge of Arabic, and then to England, where she had been placed in social housing in Enway. Her husband had 'gone away'. She was a Christian, and had not found any Eritrean or Christian friends from Eritrea, or the neighbouring countries, in Enway. Zula's isolation was vastly compounded by the fact that her youngest child, a boy aged nine or ten, was severely physically disabled, in a large powered wheelchair, and unable to speak or feed himself. He was in and out of hospital, and every time Zula had tried to enrol in an English class, he had fallen ill, and she had been unable to continue the classes. Sarama's older brother and sister had been 'moved out' of Enway College on to a vocational course project under threat of permanent exclusion, as they too had experienced difficulties at school. Zula told me that as her children had grown older, whilst they could understand her mother tongue, Tigrinya, and Arabic, they refused to speak anything but English- of which she could only understand a few words and phrases. This had compounded her children's behaviour problems because they often pretended not to understand her and would not answer her when they did. When they translated for her into English, both with me at their home and at school meetings, they often treated her crossly, as a mother might an annoying child. This was perhaps caused by the unfamiliar balance of power presented to a child when they are asked to translate into the dominant language (in this case, English) and their parent is engaged in a discussion about that same child's misdemeanours with an authority figure. 
As with many of the students I supported in Enway, the Enway College Inclusion Manager $^{22}$ told me that she thought Zula could understand everything that was said to her in English, and was 'pretending' to understand less than she did. But it became clear that Zula did not understand the important finer details. She thought, for example, that her older two children had had no choice when they were moved out of Enway College into the vocational programme, because she had missed the fact that they were not actually permanently excluded, but only being threatened with permanent exclusion.

After several phone calls and explanations, a translator was obtained for a crisis meeting about Sarama, and I had hopes that it would be a turning point for Zula's ability to advocate for her children. The translator that arrived at the school was a Saudi Arabian Muslim man, neatly dressed in a grey suit, and he spoke Arabic Zula's second language. But his mouth fell open and he started to shake his head as the teachers described how Sarama would shout at teachers and refuse to go into class. He was appalled at Sarama's behaviour, and broke off in the middle of the meeting to instruct Zula in what he thought she should be doing as a parent. Zula, tears streaming down her face, seemed to be irritated by this and unable to concentrate on the discussion, patting her yellow head wrap and turning away from him, shaking her head. She did not want him to translate a second time, and asked for an Eritrean, a woman, or a Christian translator, none of which the Enway Translation Service could locate. It seemed that despite having gone through the process twice with her older children, Zula's lack of English had deeply affected her ability to advocate on behalf of her third child, and prevent, as she desired, yet another move (posited as a way to 'avoid' a third permanent exclusion) to a vocational education placement. Despite her hopes, none of her children attained a grade in the national examinations (GCSEs). ${ }^{23}$

\section{Kim}

Whilst most of the inclusion staff I met in Enway schools did not know that a translation service was available and funded, they often relied on teachers - and sometimes on other students - to translate at meetings. Kim, a Vietnamese student

\footnotetext{
${ }^{22}$ A senior teacher whose work includes supporting previously excluded students and those with special educational needs into their school.

${ }^{23}$ General Certificate of Secondary Education.
} 
from Pope John Paul Catholic School, came through the 'Hard to Place' Student Placement Panel to be sent to a new school on a 'managed move' following an incident of theft. All the other head teachers at the Panel were very angry with Kim's head teacher for effectively excluding a student for what they saw as 'a one-off incident'. Of course because this was 'a managed move' - ostensibly an optional move which Kim's parents had to agree to (under threat of an official exclusion) there was no governors' hearing or appeal, as there was no permanent exclusion.

Kim was placed at Ennon Grand Academy, and the school was asked to arrange a Vietnamese interpreter to support her father at the reintegration meeting. Unfortunately, upon arrival at Ennon Grand, I found that the interpreter had not been arranged. The Head of Year $^{24}$ told me that he had an older 'straight-A student' who could speak Vietnamese, and invited him into the meeting. Kim told the meeting what happened: 'Me and my girls we went into the changing rooms and took an i-Pod', she explained candidly. The older student's eyes bulged at this. Kim's dad sat at the table blinking. The student translator did not say a word, and sat through the meeting as Kim translated for her father. Through Kim, he told us that the family was Catholic and that he was very upset and angry and disappointed that Kim had to go to a nonCatholic school, and felt that 'even perfect students make mistakes'. For him, as for the Panel members, the fact it was a one-off incident with no prior issues was the problem.

On the way out of the building after the meeting Kim told me that her head teacher at Pope John Paul had told her that if she 'told the truth' she may be able to stay at Pope John Paul. So she told the truth. And she had been pushed into a 'managed move' to another school anyway. I explained that she was not officially permanently excluded, but it did not matter to Kim that she had not had the governor's meeting required to ratify or quash all official permanent exclusions. To her and her father, the result was that she had been excluded, permanently. Kim’s experience demonstrates the extra vulnerability of an unofficially excluded student whose parent does not speak English. Her 'translator', a student at her new school, could potentially have left the room and told all his friends sensitive details about the new girl entering their school. And her

\footnotetext{
${ }^{24}$ A senior teacher responsible for the pastoral care of the year-group or class.
} 
father had been unable to advocate on her behalf, or to access the information he needed to challenge the managed move.

\section{Age assessments}

Another barrier to appropriate support for students who were at risk of permanent exclusion was that, if they were not born and raised in the UK, they were often viewed with suspicion at the Panel with regard to their age. When young people enter the country without identifying paperwork, often as asylum seekers, they have their age assessed by a doctor and entered onto their arrival papers by immigration officials. These young people sometimes arrive in schools with paperwork stating an age which some teachers suspect to be false. One young woman whose case came to Panel, a refugee from war-torn Afghanistan, was generally thought to be twenty-three or twenty-four years old when she arrived in Enway and was placed in a mainstream school in Year $10^{25}$. Her violent behaviour - hitting and punching her classmates - led to her being permanently excluded from school, and she was placed in New Start, an alternative education placement for seriously violent or aggressive permanently excluded students on Enway High Street. When she attacked a member of the public outside New Start, she became one of the very few students they permanently excluded, and was quickly placed at a second alternative education placement. Had this student been viewed as actually fifteen years old, she might have been referred for CAMHS ${ }^{26}$ services for help with anger management. But because of her perceived age, her placement needs were simply seen as 'containment' until her papers said she was sixteen and she was no longer the responsibility of the Enway Local Authority. If she was actually in her twenties, she would have been better served by adult services focusing on employment than on a children's service focussed on containment. Assessing age was felt very much to be something the Panel had no control of - it was something done by unnamed immigration officials in another part of the country - but it did not stop the speculation. In this case, it prevented access to a service which could perhaps have prevented a permanent exclusion. As in the case of language (discussed above), immigration services, including age assessments, may be identified as another of Eriksen's 'social boundaries between groups' (1995). They can thus be seen as another factor leading to inequities in the administration of permanent

\footnotetext{
${ }^{25}$ Most students in Year 10 are fourteen to fifteen years old.

${ }^{26}$ Child and adolescent mental health services.
} 
exclusion from school resting on the basis of a socio-ethnic boundary. These inequities, I argue, amount institutional racism.

\section{Assumptions made on the basis of skin colour labels: Jed}

Jed's case also constituted an opportunity for Panel attendees to make assumptions based on the provided paperwork. It is a good example of how it is probably more useful to talk about the attitudes towards 'race' and ethnicity of those in authority than the essentialised perceived experiences of particular groups of students (Hall 1992; Gilroy 1998; Ball et al. 2002; discussed above).

During the 36 months I attended the Panel - once every two weeks - I observed a sense of relief amongst Panel members each time a 'Hard to Place' young person was contained in a young offender's secure institution. ${ }^{27}$ On exit, however, these young people presented the Panel with a reluctant responsibility to find a school place. Jed's paperwork, which identified (and essentialised) him as a 'WBRI' ${ }^{28}$ boy of fifteen, was introduced to the Enway Panel by his youth offending team officer. He was coming out of a secure unit where he had been serving a sentence for robbery, and wanted to go to Knightsdown College in Enway because he had heard that it was 'a good school'. Panel members were reluctant to give him a placement at mainstream school. Before the secure unit, Jed had been permanently excluded and had spent time in a pupil referral unit. Since leaving what everyone called 'Secure', Jed had spent several weeks sleeping rough, and had run away from his foster carer to go home to his heroin addicted mother. He was now to be placed with his grandmother, and was keen to get his life back on track.

Jed was already contending with a history not usually looked on kindly by the Panel. But when I saw in the paperwork that he had said that 'other white boys' at his previous school had 'been racist' to him, my heart sank in anticipation. I knew that the Panel would question his 'right' to claim racism. Jed's social worker had attended the Panel, and explained that his friends were all reported to be 'BCRB', 'BAFR' or

\footnotetext{
${ }^{27}$ Prison for young people.

28 'White British' in the standard government-recommended 'ethnic monitoring codes', which had been developed on the basis of the 2001 population census (Department for Education and Skills b).
} 
'BOTH'29 and that he liked to dress and talk like his friends and listen to rap and hip hop music. She explained that it was because of this that his 'white' peers had bullied him and that he had complained of racism. But this above all else was what the Panel derided in their reading of the papers. Jed's claim to having been a victim of racism was seen as more problematic than his wish to try mainstream school after months in a secure unit.

Jed was subjected here to what has been identified as a racism drawn towards 'a white person's' association with 'black people'- something experienced by the often 'white' mothers of 'dual heritage' children ${ }^{30}$ (Blair 2001). His youth offending team worker told me that he was extremely frustrated by the Panel's lack of empathy and understanding. He felt that Jed had learned to 'manage himself' in the young offender's institution and deserved to make 'a fresh start'. But the Panel did not make a placement. They employed a delaying tactic, sending the case back 'for more information'.

Jed's case suggests that assumptions made on the basis of skin colour labels constitute a 'social boundary between groups' (Eriksen 1995). It is important to note here Halls' (1992) concern that 'the embattled, hegemonic conception of 'Englishness' ... does not represent itself as an ethnicity at all' (Hall 1992:257). Importantly in the context of this article, however, it points to an official conceptualisation of identity and experience linked to a system of reductive skin colour labels.

Whereas Jed had already been permanently excluded, Ishaq, discussed below, was still in his mainstream school when I first met him.

\section{Differences between the discourses parents and school professionals are authorised} to use: Ishaq

Ishaq's case very clearly addresses the concept of institutional racism in relation to school exclusions. It represents an ideological tussle right on the social boundaries

\footnotetext{
${ }^{29}$ Again, it is important to point out that these codes essentialise the experience of a constructed category of people. These stand for 'Black Caribbean'; black African', or 'black other' in the 'ethnic monitoring codes'. These, as in many urban areas in England, lacked the detail Enway research officers wanted to gather, and so the list in Enway was more detailed that the government-recommended list.

${ }^{30}$ The phrase sometimes given to describe children whose parents are understood to have different cultural and/or ethnic backgrounds.
} 
between groups, and concerns the differences between the discourses parents and school professionals are (socially) authorised to use in discussing a young person's behaviour.

Ishaq's mother told me that she had been born to a 'white English mother' and 'a Jamaican father', Moses. Moses was a well-educated education activist who gave lectures on inclusive education for a university and had been involved in several community youth schemes. He was also a Rastafarian. The family was proud of its African heritage and Ishaq had been named after an ancient Egyptian prince. Every male member of the family played in their successful semi-professional jazz band. Ishaq, who played the trumpet in the family band, was a tall boy with a charming smile, and had been attending Ennon Castle School for two years. Now aged fourteen, he was beginning to wear the patience of his teachers, and was often in trouble for running down the corridors during class times, climbing out of windows, threatening his peers, and walking away from senior teachers when they were telling him to calm down. Because of this he was deemed at risk of permanent exclusion for 'persistent disruptive behaviour' and his mother was called into several school meetings to discuss what could be done. Moses would sit in these meetings and patiently explain that he thought his grandson was 'a victim of institutional racism' characterised by 'a curriculum that does not hold Ishaq's attention' and a set of teaching strategies 'not designed to cope with his physicality'. He and his daughter, Ishaq's mother, were tenacious in their assertion that Ishaq had a right to a relevant school experience; one which would catch and hold his attention, empathise with his lived experience, and offer a constructive focus for his energy.

The school and the family were deeply polarised in their views: Ishaq's head of year told me that he was 'a cheeky boy of medium intelligence who's allowed to do as he pleases at home'. The Inclusion Manager complained that his mother 'totally undermined' their authority by challenging every instance of alleged misdemeanour and the processes through which Ishaq was being supported. They had never heard Ishaq play the trumpet and felt that the family was exaggerating his musical abilities. They had asked an educational psychologist (EP) to assess him and attend his Pastoral Support Planning meetings (explained above) as his mother had asked repeatedly for this, but felt that this was unnecessary and that Ishaq was 'taking up valuable EP 
time'. They broadly ignored Moses and the intellectualised deconstruction of events he offered at every meeting. They were highly suspicious of the family, who over the weeks and months appeared to be becoming increasingly upset. The family wrote to the school, saying that Ishaq was the victim of constant and unrelenting surveillance; that he was 'always the first student the teachers blamed' for any problem; and that he was highly intelligent and underserved by a curriculum and an education system not developed for 'Black Caribbean-British boys'. They also felt that the systems in place to support Ishaq were inadequate and poorly applied.

Called into the vast breach between the school and the family, the sympathetic educational psychologist was able to inject some empathy into the meetings we held and helped to keep discussions focussed on support strategies and on trying to understand the barriers to learning that Ishaq was experiencing. But the gulf between the school and family was broad and deep, and after three years of monthly meetings Ishaq was permanently excluded. His family scraped the money together and sent him to a boarding school rather than allowing him to go to the Enway Pupil Referral Unit. They felt that as 'a Black Caribbean boy living in England', a quality education was a key to success for Ishaq.

The concerns raised by Ishaq's grandfather - that the English school system was not designed for Caribbean-English boys - are echoed in Blair (2001), who explains that '[t]he racial legacy of Europe generally and of Britain's specific historical relations with many parts of the world can still be found in our schools today' (8). Blair (ibid) also identifies the development of assumptions about a perceived 'essential criminality of black people' (37), echoing one of Moses' greatest concerns. Gilroy (1987) states that:

The representation of black men as having particular tendencies ... has ... justified their closer surveillance by the police and in school; has justified their exclusion from school and their constant presence before the criminal justice system ... It fed in teachers ... the widespread belief that ... Afro-Caribbean students were especially prone to threatening teachers' authority. 37-38

Ishaq's family's cultural identity, discussed, performed and evidenced in their historically-referenced names, music, and intellectual interests, provided them with a 
critical framework for understanding the difficulties he was having at school. Ignored in the school meetings, however, cultural identity constituted an element of a discourse not enjoined by his teachers, and this may have been one of the factors that resulted in his ultimate exclusion from school. Even if Ishaq's behaviour was difficult to deal with, engagement in a frank discussion about ethnicity in the education system would have offered an element of visibility to the ethnicity element of Ishaq's experience and would have helped the school to work collaboratively with the family, to share a critical language, and to turn a critical eye on its on its own processes. But the family and the school parted company with the school convinced that Ishaq was being seriously educationally neglected by his family through a perception that they were 'undermining' the school's disciplinary procedures, and the family unconvinced that the school was committed to offering an effective, empowering education for their son. The dissonance between the discourses could be said to have been created and exacerbated by a social boundary between the two groups (Eriksen 1995) - the differences between the discourses parents and school professionals are (socially) authorised to use in discussing a young person's behaviour. That lack of access to what could have been a useful lens through which to address the problems Ishaq was experiencing constitutes evidence of institutional prejudice.

\section{Conclusion}

Despite the consistently high visibility of systemic prejudice on the basis of 'race' and ethnicity in the literature on exclusion from school (DePear and Garner 1996; Gillborn and Youdell 2000; Blair 2000; Cooper 2002; Osler and Vincent 2003; Wright 2005), I did not hear racism being directly addressed in discussions held within Enway Children's Services, schools, and the 'Hard to Place' Student Placement Panel. There were plenty of conversations about 'celebrating diversity', but nothing about directly addressing incidents of racism. Racism seemed to be invisible and inaudible.

However, the administration of exclusion from school in Enway revealed a series of issues related to the social boundaries between people that negatively affect students at risk of or subject to permanent exclusion to the extent that they might constitute 'institutional racism'. The high statistical currency, for example, of the English 
language was shown to exacerbate the negative effects of an instance of exclusion. Lack of adequate translation facilities were also shown to undermine the participation of parents in exclusion and inclusion processes. The issue of age assessments for immigrant and refugee children can also be seen to institutional responses to individual cases. Jed's claim to being a recipient of racism was met with ridicule because his whiteness meant he was seen as non-'ethnic': evidence that assumptions were being made on the basis of reductive skin-colour labels. And Ishaq was unable to benefit from his family's knowledge and articulacy because of a disconnect between the discourses that school and family were socially authorised to adopt.

Why did I choose to focus, out of everything in the education system, specifically on permanent exclusion? It was, of course, my area of work. But more importantly, I chose this area because its quality of exclusivity concentrates attention on what might need to change within the English education system as a whole. Over the last seven years in the UK, almost 10,000 of the pupils for whom the mainstream 'inclusive' system was designed were permanently excluded from it - not to mention those who were 'unofficially excluded' - (DfEE ${ }^{31}$ 1999c; DfEE 2001; DCSF ${ }^{32}$ 2009). An ineqitable proportion of those students were recorded as belonging within a 'black or minority ethnic' category. This study of permanent exclusion from school reveals and untangles the threads of a tapestry of institutional racism woven throughout the system. It also suggests that institutional racism may be exacerbated in cases of school exclusion, crystallised under the pressure of that critical incident. It follows that institutional racism in the education system in England must be acknowledged and challenged by those responsible for the policy and prctice of schooling.

\section{References}

Anzaldua, Gloria. 1987. Borderlands: Las Fronteras- the New Mestiza. San Francisco: Aunt Lute Books.

Archer, L and Yamashita, H. 2003. Theorising Inner-city Masculinities: 'race', class, gender and education. Gender and Education. 15:2 115-132.

Back, Les. 2008. London calling: Multiculture and the war on terror's nervous system. Identity and Social Justice Group Inaugural Seminar. Department of Educational Studies, Goldsmiths, University of London. October 7.

\footnotetext{
${ }^{31}$ UK Government Department for Education and Employment, now the Department for Children, Families and Schools

${ }^{32}$ Department for Children, Families and Schools
} 
Back, Les and John Solomos, Eds. 2000. Theories of race and racism. Oxon: Routledge.

Ball, S, Reay, D, and David, M. 2002. 'Ethnic Choosing': minority ethnic students, social class and higher education choice. Race Ethnicity and Education. 5:4, 333-357.

Blair, Maud. 2001. Why pick on me? School exclusion and Black youth. Stoke on Trent: Trentham Books Ltd.

Bourdieu, Pierre and John-Claude Passeron. 1977. Reproduction in Education, Society and Culture. London: Sage Publications.

Butler, Judith. 1999, first published 1990. Gender Trouble. Routledge: London.

Carlile, A. 2010. Docile bodies or contested space? Working under the shadow of permanent exclusion. International Journal of Inclusive Education. 24 August 2010 (iFirst).

Cooper, Charlie. 2002. Understanding school exclusion: challenging processes of docility. Nottingham: Education Now Publishing Cooperative.

DePear, Susan and Philip Garner. 1996. Tales from the exclusion zone: the views of teachers and pupils. In Blyth, Eric and Judith Milner, Eds. 149-161. Exclusion from school: inter-professional issues for policy and practice. London: Routledge.

Department for Education and Skills. April 2004. Aiming High: Guidance on supporting refugee and asylum seeking children. DfES/0287/2004

Department for Education and Skills b. Ethnic minority achievement data collection. http://www.standards.dfes.gov.uk/ethnicminorities/faqs/763517/\#10

Eriksen, Thomas Hylland.1995. Small places, large issues: An Introduction to Social and Cultural Anthropology. London: Pluto Press.

Evans, Gillian. 2007. Educational failure and working class white children in Britain. Hampshire: Palgrave Macmillan.

Foucault, Michel. 1977. Discipline and Punish: the birth of the prison. Harmondsworth: Penguin Books. Trans. A Sheridan.

Francis, Becky. 2005. Not/Knowing their place: Girls' classroom behaviour. In Lloyd, Gwyneth Ed. 9-22. Problem Girls: Understanding and supporting troubled and troublesome girls and young women. Oxon: RoutledgeFalmer.

Freire, Paulo. 1996. Pedagogy of the Oppressed. London: Penguin Books.

Giddens, Anthony. 1986. The Constitution of Society. Oxford: Blackwell Publishing Ltd. 
Gillborn, D 2009. Who's afraid of critical race theory in education? A reply to Mike Cole's 'The color-line and the class struggle'. Power and Education. 1: 1, 125-131.

Gillborn, David and Deborah Youdell. 2000. Rationing Education: Policy, practice, reform and equity. Buckingham: Open University Press.

Gilroy, Paul. 1987. There Ain't No Black in the Union Jack: the cultural politics of race and nation. London: Routledge.

Gilroy, P. 1998. Race ends here. Ethnic and Racial Studies. 21:5, 838-847.

Hall, Stuart. 1992. New ethnicities. In Donald, James and Ali Rattansi, eds. 252-259. 'Race', Culture and Difference. London: Sage Publications.

Macpherson, W 1999.. The Stephen Lawrence Inquiry. Stationery Office UK government. http://www.archive.officialdocuments.co.uk/document/cm42/4262/4262.htm

Office of National Statistics. GCSE and Equivalent Average Point Scores for Young People by Ethnic Group, Referenced by Location of Student Residence 2004 - 2007. ONS.

http://neighbourhood.statistics.gov.uk/dissemination/LeadTableView.do?a=3\&b=276 753\&c $=$ Greenwich\&d $=13 \& \mathrm{e}=5 \& \mathrm{~g}=333611 \& \mathrm{i}=1001 \mathrm{x} 1003 \times 1004 \& \mathrm{~m}=0 \& \mathrm{r}=1 \& \mathrm{~s}=122$ 6851538500\&enc $=1 \&$ dsFamilyId $=1643$

Osler, Audrey and Kerry Vincent. 2003. Girls and exclusion: Rethinking the agenda. RoutledgeFalmer: London.

Rattansi, Ali. 1992. Changing the subject? Racism, culture and education. In Donald, James and Ali Rattansi, Eds. 11-48. 'Race', culture and difference. London: Sage Publications.

Rose, Nikolas. 1999. Governing the Soul: The shaping of the private self. 2nd Ed. London: Free Association Books.

Sivananden, Ambalavener. 2005. Why Muslims reject British values. The Observer, 16 October.

Skeggs, Beverley. 1997. Formations of Class and Gender. London: Sage Publications.

Solomos, John and Les Back. 2000. In Back, Les and John Solomos, Eds. 1-32. Theories of race and racism. Oxon: Routledge.

Machpherson, W 1999.. The Stephen Lawrence Enquiry: report of an enquiry by William Macpherson of Cluny presented to Parliament by the Secretary of State, February 1999. UK government.

http://www.archive.official-documents.co.uk/document/cm42/4262/4262.htm 
Tomlinson, S 2005. Race, ethnicity and education under New Labour. Oxford Review of Education. 31:1, 153-171

Wright, CY, Weekes, D and McGlaughlin, A. 1999. Gender-blind racism in the experience of schooling and identity formation. International Journal of Inclusive Education. 3:4, 293-307

Wright, Cecile. 2005. Black femininities go to school: how young black females navigate race and gender. In Lloyd, Gwynedd Ed.103-113. Problem Girls: Understanding and supporting troubled and troublesome girls and young women. Oxon: RoutledgeFalmer.

Zizek, Slavoj. 2000. Enjoy your nation as yourself! In Back, Les and John Solomos Eds. Theories of race and racism. Oxon: Routledge

Zizek, Slavoj. 2008. Violence. London: Profile Books Ltd. 